
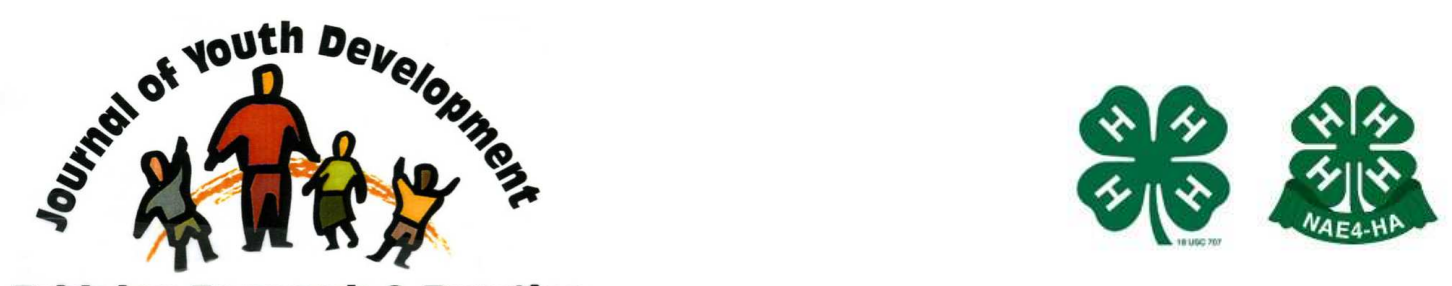

Bridging Research \& Practice

\title{
Perceptions of 4-H Extension Educators and Volunteer Leaders toward the Inclusion of Youth with Attention Deficit Hyperactive Disorder(s) in 4-H Programs
}

\author{
Chido Mpofu \\ Department of Agricultural and Extension Education \\ Pennsylvania State University \\ University Park, Pennsylvania \\ cum133@psu.edu \\ Patreese D. Ingram \\ Department of Agricultural and Extension Education \\ Pennsylvania State University \\ University Park, Pennsylvania \\ pdi1@psu.edu \\ Rama Radhakrishna \\ Department of Agricultural and Extension Education \\ Pennsylvania State University \\ University Park, Pennsylvania \\ Brr100@psu.edu
}




\title{
JOURNAL OF YOUTH DEVELOPMENT \\ bridging research and practice

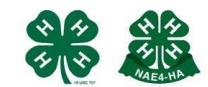

\section{Perceptions of 4-H Extension Educators and Volunteer Leaders toward the Inclusion of Youth with Attention Deficit Hyperactive Disorder(s) in 4-H Programs}

\author{
Chido Mpofu, Patreese D. Ingram and Rama Radhakrishna \\ Pennsylvania State University
}

\begin{abstract}
The challenges, attitudes, training and support systems needed by $4-\mathrm{H}$ extension educators and volunteer leaders in order to successfully and effectively include youth with Attention Deficit Hyperactive Disorder (ADHD) in their programs are discussed within this article. Data were collected from extension educators and volunteer leaders in a Northeastern state. The results revealed that 4-H extension educators and volunteer leaders are not adequately trained to include youth with ADHD despite the fact that they may have one or two children with these symptoms in their clubs. For inclusion to be meaningful for youth with ADHD we recommend training for extension educators and volunteer leaders on characteristics of ADHD, its implication for youth involvement as well as techniques/ways of meeting the learning styles of youth with ADHD.
\end{abstract}

\section{Introduction}

Attention Deficit Hyperactive Disorder (ADHD) is defined as "a persistent pattern of inattention and/or hyperactive and impulsive behavior that is more frequent and severe than is typically observed in individuals at a comparable level of development" (Efron, Sciberras, \& Hassell, 2008 , p. 187). It is one of the most common childhood neurological disorders associated with a number of behavioral, academic and social problems and can continue through adulthood (National Institute of Mental Health, 2008). An estimated $5 \%$ to $8 \%$ of children aged 4-to 17 years old in the United States have ADHD (Wheeler, Pumfrey, Wakefield, \& Quill, 2008). 


\section{Background}

As we moved into the 1990s the question "should children with disabilities be included in 4-H programs" has translated into "how and what should be done to accommodate children with disabilities" (Boone, Boone, Reed, Woloshuk, \& Gartin, 2006). These questions arose due to the signing of the Americans with Disabilities Act (ADA) in 1990 that prohibited discrimination against people with disabilities in many areas including programs funded by state and local government (Boone, et al., 2006).

The inclusion of students with special needs in formal and non-formal educational programs has been a controversial topic (Harrower \& Dunlap, 2001). In most schools inclusion has been seen as a matter of social justice and human rights as well as an issue of special needs with little attention given to the implications for mainstream colleagues. As a result, less priority has been given to considerations of what does or does not work for certain groups (Humphrey, 2008; Jordan, 2008). Jordan (2008) argues that the assumption that what is being taught in schools is relevant to all children has caused the mainstream system to remain oblivious to the diversity of the children they serve.

The lack of knowledge and expertise about disabilities and their implications for youth involvement has resulted in less quality opportunities in which youth with disabilities can participate (Tormoehlen \& Field, 1994). A study by Boone, et al., (2006) concluded that extension professionals are not adequately trained to work with special needs youth despite the fact that the majority of them have special needs youth in their programs. Extension professionals believe that including special needs youth in traditional 4-H programs enhances the development and growth of all youth involved (Boone, et al., 2006). In a study about attitudes of extension professionals towards diversity, it is noted that extension professionals generally agreed that physically and mentally challenged youth should be involved in 4-H programs, $91 \%$ and $89 \%$ respectively (Ingram, 1999).

The 4-H program is meant to help young people become productive citizens through the development of knowledge and life skills needed for one to be successful in today's competitive world (All about 4-H, 2008). 4-H should "foster engaged learning, and provide support for all youth to become active and self-regulated learners as well as creating a community of learners where everyone belongs, is accepted, supports and is supported by his or her peers, other members and leaders while their educational needs are being met" (Kent, 2008, p. 2).

Much has been done to accommodate children with physical disabilities but as more and more children are being diagnosed with emotional disabilities such as Attention Deficit Hyperactive Disorder (ADHD), the questions that arise include:

- Are today's 4-H extension educators and volunteer leaders prepared to work effectively with these children? and

- What can or is being done to meet the challenges involved in meeting the needs of these youth? 


\section{Purpose and Objectives}

The purpose of this study was to determine the challenges, attitudes, training and support systems needed by 4-H Extension educators and volunteer leaders in order to successfully and effectively include youth with ADHD in 4-H programs. The objectives of this study were to determine the:

1. Comfort level and the challenges that 4-H Extension educators and volunteer leaders might face when working with youth with ADHD.

2. Perceptions of 4-H Extension educators and volunteer leaders toward members with ADHD in 4-H programs.

3. Perceptions of Extension educators and volunteer leaders on the effectiveness of 4-H programs in promoting an environment conducive for inclusion of youth with ADHD.

4. Perceived benefits of including youth with ADHD in 4-H programs.

5. Difference in perceptions between Extension educators and volunteer leaders.

\section{Methodology}

The target population for the study was the 4- $\mathrm{H}$ extension educators and volunteer leaders at a major university in the Northeast. A central database of Cooperative Extension in this state was used to identify 4- $\mathrm{H}$ extension educators and volunteer leaders. A random sample of 384 volunteer leaders was drawn and a census $(\mathrm{N}=67)$ of the extension educators was invited to participate in this study. A multi-stage sampling procedure that included stratified random sampling and systematic random sampling was used to draw a sample of volunteer leaders for the study.

Two questionnaires (one for volunteer leaders and one for extension educators) with five sections each were developed to collect data. The instrument included adopted and modified questions and statements from two studies titled "Attitudes of Extension Professionals Towards Involvement of Special Needs Youth in 4-H Programs" (Boone, et al., 2006) and "Volunteer Leaders' Assessment of Pennsylvania 4-H Programs" (Radhakrishna, Cabot \& Everhart, 2007). The questionnaire contained 58 items.

A panel of experts reviewed the questionnaires to determine the face and content validity. The panel included three faculty members with expertise in the following areas: special education, 4- $\mathrm{H}$ youth development programs, issues of diversity, and research methodology. The questionnaires were field tested using volunteer leaders from the target state and extension educators from Maryland. Extension educators from other states were used in the field and pilot tests because the census of extension educators in the target state was included in the research study. Adjustments to the pilot instrument were made based on the feedback and recommendations from the field test. The instrument was found to have acceptable reliability. Reliability coefficient (cronbach's alpha) ranged from a low of .78 (challenges section) to a high of .98 (benefits section), with an overall reliability of .96 for the entire instrument.

For extension educators, the survey was sent electronically and participants completed the survey on line. The Survey Monkey program was used. For volunteer leaders, the survey was sent electronically for those who had included email addresses in the Cooperative Extension central data system. For those volunteer leaders who had not included an email address in the Cooperative Extension central data system, a written survey was sent through surface mail with 
a stamped addressed envelope for return of the completed survey. A three round, two-week interval format was utilized for data collection.

The quantitative data collected for this study were analyzed using the Predictive Analytic SoftWare (PASW) version 17. Descriptive statistics used in this study included frequencies, means, and standard deviations. An independent t-test (comparison of means) was used to measure the differences in the perception of extension educators and volunteer leaders. One hundred and six (106) participants responded to the survey.

\section{Findings}

The typical respondent was a white female over the age of 40 . One half of respondents had been involved with $4-\mathrm{H}$ for more than 11 years. Approximately two-thirds of respondents had attained a bachelor's degree or higher level of education.

The key findings of this study indicated that extension educators and volunteer leaders

i. find it challenging to work with youth with ADHD due to lack of training,

ii. have positive perceptions toward youth with ADHD,

iii. believe that all youth benefit from inclusion

iv. are uncertain that 4- $\mathrm{H}$ is effective in promoting an environment conducive for inclusion of youth with ADHD and

v. need training on the disorders and ways to make inclusion a success.

\section{Objective 1: Comfort Level and Challenges}

Over one-half of the extension educators and volunteer leaders indicated that they face various challenges when working with youth with ADHD. They need training on how to interact with youth with ADHD (67.3\%), and on ways to encourage youth with ADHD to work in groups with others $(65.1 \%)$. See Table 1.

Table 1

Percentages and Mean Score for Respondents; Level of Agreement on Challenges They Might Face when Working with Youth with ADHD $(\mathrm{N}=106)$

\begin{tabular}{|l|r|r|r|r|r|r|c|}
\hline Challenges & $\mathrm{S} \mathrm{D}$ & $\mathrm{D}$ & $\mathrm{N}$ & $\mathrm{A}$ & \multicolumn{2}{|c|}{$\mathrm{SA}$} & \multicolumn{2}{|c|}{ Mean Scores } \\
\hline & $\%$ & $\%$ & $\%$ & $\%$ & $\%$ & $M$ & $S D$ \\
\hline Difficulties completing tasks & 2.9 & 20.0 & 21.9 & 48.6 & 6.7 & 3.36 & 0.97 \\
\hline $\begin{array}{l}\text { Difficulties following } \\
\text { instruction/directions }\end{array}$ & 1.9 & 21.9 & 17.1 & 53.3 & 5.7 & 3.39 & 0.96 \\
\hline Need training on ways to interact & 0.9 & 4.7 & 27.1 & 43.9 & 23.4 & 3.84 & 0.87 \\
\hline Have adequate training & 11.3 & 46.2 & 31.1 & 7.5 & 3.8 & 2.46 & 0.93 \\
\hline $\begin{array}{l}\text { Need training on ways to } \\
\text { encourage working in groups }\end{array}$ & 2.8 & 2.8 & 29.2 & 50.0 & 15.1 & 3.70 & 0.86 \\
\hline
\end{tabular}

Note: $\mathrm{SD}=$ Strongly Disagree, $\mathrm{D}=$ Disagree, $\mathrm{N}=$ Neutral, $\mathrm{A}=$ Agree, $\mathrm{SA}=$ Strongly Agree 
When asked about their comfort level on including youth with ADHD about two-thirds indicated that they are moderately to considerably comfortable including youth with ADHD in their clubs (66\%), and helping youth with ADHD interact with other 4-H members (66.9\%). See Table 2.

Table 2

Percentages and Mean Scores for Respondents' Comfort Leven when

Working with Youth with ADHD ( $\mathrm{N}=106)$

\begin{tabular}{|l|r|r|r|r|r|r|r|}
\hline Comfort level & NC & SC & MC & CC & HC & \multicolumn{3}{|c|}{ Mean Score } \\
\hline & $\%$ & $\%$ & $\%$ & $\%$ & $\%$ & $M$ & $S D$ \\
\hline $\begin{array}{l}\text { Comfortable including youth with } \\
\text { ADHD }\end{array}$ & 1.9 & 6.6 & 31.1 & 34.9 & 25.5 & 3.75 & 0.97 \\
\hline Comfortable helping youth with ADHD & 2.8 & 4.7 & 31.1 & 35.8 & 25.5 & 3.76 & 0.98 \\
\hline Preparing special visual aids & 16.0 & 21.0 & 31.0 & 22.0 & 10.0 & 2.90 & 1.23 \\
\hline
\end{tabular}

Note: $\mathrm{NC}=$ Not at all Comfortable, $\mathrm{SC}=$ Slightly Comfortable, $\mathrm{MC}=$ Moderately Comfortable, $\mathrm{CC}=$ Considerably Comfortable, $\mathrm{HC}=$ Highly Comfortable

\section{Objective 2: Perceptions of Extension Educators and Volunteer Leaders}

The perceptions of the respondents toward youth with ADHD were mostly positive. Results show that $98.1 \%$ of the respondents perceive youth with ADHD as productive members in society, $83.9 \%$ believe that the inclusion of youth with ADHD provides good experience for other members, $76.2 \%$ believe that inclusion promotes growth for youth with ADHD and $77.3 \%$ are willing to accept youth with ADHD as 4-H members. With regard to whether youth with ADHD are best served by separate clubs, most respondents $82.1 \%$ did not feel that separate clubs are the answer, in addition $94.4 \%$ did not believe that youth with ADHD have learning difficulties that cannot be helped by 4-H. See Table 3. 
Table 3

Percentages and Mean Scores for Respondents Holding Various Perceptions Regarding Youth with ADHD ( $\mathrm{N}=106)$

\begin{tabular}{|l|r|r|r|r|r|r|r|}
\hline Perception of youth with ADHD by leaders & SD & $\mathrm{D}$ & $\mathrm{N}$ & $\mathrm{A}$ & $\mathrm{SA}$ & \multicolumn{3}{|c|}{ Mean Scores } \\
\hline & $\%$ & $\%$ & $\%$ & $\%$ & $\%$ & $\mathrm{M}$ & $S D$ \\
\hline Productive members in society & 0.0 & 0.0 & 1.9 & 36.8 & 61.3 & 4.59 & 0.53 \\
\hline Willingness to accept youth with ADHD & 0.9 & 2.8 & 18.9 & 46.2 & 31.1 & 4.04 & 0.84 \\
\hline $\begin{array}{l}\text { Inclusion provides good experience for other } \\
\text { members }\end{array}$ & 0.9 & 2.8 & 12.3 & 54.7 & 29.2 & 4.08 & 0.78 \\
\hline Need special training on how to work with ADHD & 0.0 & 8.5 & 22.6 & 42.5 & 26.4 & 3.87 & 0.91 \\
\hline 4-H clubs promote growth for youth with ADHD & 1.0 & 2.9 & 20.0 & 53.3 & 22.9 & 3.94 & 0.79 \\
\hline $\begin{array}{l}\text { Youth with ADHD have disruptive behavioral } \\
\text { problems }\end{array}$ & 1.9 & 27.4 & 41.5 & 27.4 & 1.9 & 3.00 & 0.84 \\
\hline $\begin{array}{l}\text { Youth with ADHD take away time from other } \\
\text { members }\end{array}$ & 8.5 & 44.3 & 30.2 & 14.2 & 2.8 & 2.58 & 0.93 \\
\hline $\begin{array}{l}\text { Youth feel uncomfortable with a member with } \\
\text { ADHD }\end{array}$ & 8.8 & 49.0 & 26.5 & 15.7 & 0.0 & 2.49 & 0.86 \\
\hline $\begin{array}{l}\text { Youth with ADHD are best served by separate } \\
\text { clubs }\end{array}$ & 33.0 & 49.1 & 14.2 & 1.9 & 1.9 & 1.91 & 0.85 \\
\hline $\begin{array}{l}\text { Behaviors of youth with ADHD set an undesirable } \\
\text { example }\end{array}$ & 26.4 & 50.5 & 17.9 & 5.7 & 0.0 & 2.03 & 0.82 \\
\hline $\begin{array}{l}\text { Youth with ADHD have learning difficulties 4-H } \\
\text { cannot help them with }\end{array}$ & 60.3 & 34.0 & 3.8 & 1.9 & 0.0 & 1.47 & 0.66 \\
\hline
\end{tabular}

Note: $\mathrm{SD}=$ Strongly Disagree, $\mathrm{D}=$ Disagree, $\mathrm{N}=$ Neutral, $\mathrm{A}=$ Agree, $\mathrm{SA}=$ Strongly Agree

Objective 3: Perceptions of Extension Educators and Volunteer Leaders on Effectiveness of 4-H One of the study's objectives was to determine the perceptions of extension educators and volunteer leaders on the effectiveness of 4-H programs in promoting an environment conducive for inclusion of youth with ADHD. Most of the respondents were uncertain and/or perceived 4-H to be ineffective in promoting a conducive environment. Of the 10 items only two were rated as effective by more than $50 \%$ of the respondents. Sixty-eight percent $(68.3 \%)$ of the respondents believe that $4-\mathrm{H}$ is effective to very effective when it comes to providing programs in which all youth can participate, and developing opportunities for broadening personal experience for all participants (52.8\%). See Table 4. 


\section{Table 4}

Percentages and Mean Scores for Respondents Regarding the Effectiveness of 4-H Programs in Promoting an Environment Conducive for Inclusion of Youth with ADHD $(\mathrm{N}=104)$

\begin{tabular}{|l|r|r|r|r|r|r|r|}
\hline Perceptions on effectiveness & VI & I & N & E & VE & \multicolumn{3}{|c|}{ Mean Score } \\
\hline $\begin{array}{l}\text { Defining ADHD and its implication to youth } \\
\text { involvement }\end{array}$ & $\%$ & $\%$ & $\%$ & $\%$ & $\%$ & $M$ & $S D$ \\
\hline $\begin{array}{l}\text { Providing guidance on how to work with youth with } \\
\text { ADHD }\end{array}$ & 7.8 & 35.9 & 46.6 & 9.7 & 1.0 & 2.62 & 0.79 \\
\hline Providing programs in which all youth can participate & 0.0 & 3.8 & 27.9 & 48.1 & 20.2 & 3.85 & 0.79 \\
\hline $\begin{array}{l}\text { Developing projects that are appropriate for youth } \\
\text { with ADHD }\end{array}$ & 1.0 & 15.7 & 48.0 & 27.5 & 7.8 & 3.25 & 0.85 \\
\hline Making leaders aware of children with ADHD & 3.8 & 28.8 & 45.2 & 19.2 & 2.9 & 2.88 & 0.86 \\
\hline $\begin{array}{l}\text { Providing skills needed to lead projects for youth } \\
\text { with ADHD }\end{array}$ & 3.9 & 39.8 & 37.9 & 14.6 & 3.9 & 2.75 & 0.89 \\
\hline Providing training on inclusion of youth with ADHD & 11.5 & 35.6 & 41.3 & 7.7 & 3.8 & 2.57 & 0.93 \\
\hline Providing alternative projects for youth with ADHD & 5.8 & 38.8 & 44.7 & 9.7 & 1.0 & 2.61 & 0.79 \\
\hline $\begin{array}{l}\text { Developing opportunities for broadening personal } \\
\text { experience }\end{array}$ & 1.0 & 10.6 & 35.6 & 36.5 & 16.3 & 3.57 & 0.92 \\
\hline Promote self esteem for youth with ADHD & 0.0 & 12.5 & 39.4 & 36.5 & 11.5 & 3.47 & 0.86 \\
\hline
\end{tabular}

Note: $\mathrm{VI}=$ Very Ineffective, I=Ineffective, $\mathrm{N}=$ Neutral, $\mathrm{E}=\mathrm{Effective,} \mathrm{VE}=$ Very Effective

\section{Objective 4: Perceived Benefits of Including Members with ADHD In 4-H Programs}

The respondents believe that 4-H members benefit much from the inclusion of members with ADHD in 4-H programs. They believe that because of inclusion of youth with ADHD, other 4-H members learn how to communicate with people different from themselves $(75.2 \%)$, gain relationship building skills (79.2\%) and learn that everyone has their own strengths and weakness (80.2\%). In addition, the data also show that leaders believe that other members learn to be less prejudiced and see other person's unique abilities instead of disabilities (75.3\%). Youth learn to focus on the strengths and positive attitudes of others $(76.2 \%)$. Respondents also believe that youth with ADHD benefit from an inclusive 4-H program. Seventy-three percent (73\%) believe that youth with ADHD learn communication skills, 74\% relationship building skills, and $72 \%$ decision-making skills. Furthermore, $73 \%$ of the leaders believe that youth with ADHD achieve greater confidence around others, and learn to be responsible for themselves (71\%). See Table 5.

The study also sought to determine the incidences of ADHD in 4-H clubs. Our study found the incidences of ADHD in $4-\mathrm{H}$ to be comparable to the national average of $5 \%$ to $8 \%$. 


\section{Table 5}

Percentage and Mean Scores for Respondents Regarding the Benefits of Including Youth with ADHD in 4-H Programs for Other Members ( $\mathrm{N}=101)$

\begin{tabular}{|l|r|r|r|r|r|r|r|}
\hline As a result of inclusion other members learn: & VL & $\mathrm{L}$ & $\mathrm{N}$ & $\mathrm{M}$ & $\mathrm{VM}$ & \multicolumn{3}{|c|}{ Sean } \\
\hline & $\%$ & $\%$ & $\%$ & $\%$ & $\%$ & $M$ & $S D$ \\
\hline Skills useful in dealing with conflicts & 2.0 & 6.9 & 29.7 & 47.5 & 13.9 & 3.64 & 0.88 \\
\hline Communication Skills with different people & 1.0 & 5.0 & 18.8 & 58.4 & 16.8 & 3.85 & 0.79 \\
\hline Relationship building skills & 0.0 & 3.0 & 17.8 & 60.4 & 18.8 & 3.95 & 0.70 \\
\hline $\begin{array}{l}\text { That everyone is different/ has strengths and } \\
\text { weakness }\end{array}$ & 0.0 & 2.0 & 17.8 & 57.4 & 22.8 & 4.01 & 0.70 \\
\hline To be less prejudiced & 0.0 & 2.0 & 22.8 & 61.4 & 13.9 & 3.87 & 0.66 \\
\hline To focus on strengths and positive attitudes & 0.0 & 2.0 & 21.8 & 56.4 & 19.8 & 3.94 & 0.70 \\
\hline New techniques of working with youth with ADHD & 4.0 & 17.8 & 42.6 & 27.7 & 7.9 & 3.17 & 0.95 \\
\hline To be more accepting of youth with ADHD & 1.0 & 8.9 & 34.7 & 41.6 & 13.9 & 3.58 & 0.87 \\
\hline That everyone can do some things better than others & 1.0 & 5.0 & 24.8 & 44.6 & 24.8 & 3.87 & 0.88 \\
\hline
\end{tabular}

Note: $\mathrm{VL}=$ Very Little, $\mathrm{L}=$ Little, $\mathrm{N}=$ Neutral, $\mathrm{M}=$ Much, $\mathrm{V}=$ Very Much

Objective 5: Differences in Perceptions Between Extension Educators and Volunteer Leaders An independent t-test was conducted to determine if there was a difference in perceptions of extension educators and volunteer leaders toward the inclusion of youth with ADHD in 4-H programs. There was no significant difference between the perceptions of extension educators and volunteer leaders.

Qualitative questions of this study were designed to capture information on the training related to inclusion of youth with ADHD that 4-H extension educators and volunteer leaders have attended in the past and may be interested in attending. Additionally, the study sought to determine if there are any needs related to working with youth with ADHD that are not being met by the 4-H club or advisory committee of their county extension office. Leaders were asked to explain their need and give suggestions on how they thought these needs could be met. Most of the respondents reported that they had no prior training related to working with youth with ADHD. None of those who had been trained received the training through 4-H. Twentyseven (27) volunteer leaders and 14 extension educators indicated that they had received prior training.

When asked about the type of training that they would be interested in attending, leaders and educators gave a number of subject areas related to inclusion of youth with ADHD they would be interested in receiving. Topics generally focused on alternative educational methods and effective techniques that can make inclusion more productive and successful.

\section{Discussion}

Literature reveals that educators' confidence and effectiveness in working with children with ADHD is strongly related to training and experience (Weyandt, 2007). The findings of this study 
indicated that leaders lack adequate training to work with youth with ADHD. Leaders and educators need training on how to interact with, and encourage youth with ADHD to work in groups with others. Surprisingly when asked about their comfort level of helping youth with ADHD interact with other 4-H members, a considerable percentage of respondents indicated that they are moderately to considerably comfortable even though almost three-quarters of them indicated they need training on how to interact with youth with ADHD themselves. Overall, over one-half of the respondents in this study indicated that they are moderately to considerably comfortable including youth with ADHD in their clubs. But does that mean they are willing to go the extra mile to ensure that the inclusion is meaningful for these youth?

These results raise a number of questions:

i. if leaders are not aware of youth with ADHD in their program how can these youth be helped?

ii. if leaders do not know or think that the 4-H environment is conducive for the inclusion of youth with ADHD in terms of providing support and resources needed for meaningful inclusion, is 4-H taking steps to meet its goal of providing similar experience for all members?

The mission of $4-\mathrm{H}$ is to help youth develop life skills and empower all youth and their families through the provision of opportunities for youth to get involved in activities that are unique to their abilities (Tatman, 2008). 4-H programs provide opportunities for all youth with and without disabilities to get involved, gain life skills, develop self confidence, and self reliance (Tatman, 2008). This study revealed that 4-H leaders and educators believe that all members benefit from the inclusion of youth with ADHD in 4-H programs. However, most of the respondents were uncertain or thought that 4- $\mathrm{H}$ was ineffective in promoting an environment conducive for the inclusion of youth with ADHD.

4-H leaders and educators need training on the ways to effectively include youth with ADHD. In this study, more than half of the respondents indicated that they have no formal training working with youth with ADHD. A total of 41 respondents indicated that they have been trained on working with youth with ADHD but none of them received the training through 4-H. Most of the trained leaders were educators/school teachers who got trained to accommodate children with ADHD in their classrooms.

Most respondents indicated that they are struggling with adapting projects books to suit youth with ADHD. Leaders and educators need training on how to adapt the project books to make them appropriate for youth with ADHD and how to present project material in ways that can be easily comprehended by youth with ADHD. Respondents also expressed their wishes to learn about ways to encourage youth with ADHD to work in groups with others, and to learn about alternative education methods and effective techniques to help these youth become more productive and successful.

Some of the leaders and educators indicated that they do not have the basic understanding of the characteristics of ADHD. According to the literature, the lack of basic understanding can result in leaders having minimum confidence in their ability to establish a behavior contract with children with ADHD (Efron, Hassel, \& Sciberras, 2008; Hewitt, 1999). 
Leaders indicated that they are interested in understanding the characteristics of ADHD, the issues and problems associated with it and are also interested in gaining information on:

- Topics that can hold the interest of youth with ADHD

- How to handle and accommodate youth with ADHD in their 4-H club settings

- Ways to help others understand and accept youth with ADHD

- Techniques of disciplining, and setting expectations for children with ADHD

- Making club meetings more hands-on and suitable for different learning styles other than ADHD

- Working with youth with special needs such as autism and other developmental disorders

- "dealing with parents of children with ADHD as they often drop off kids and leave without explaining their child's special needs, and using $4 \mathrm{H}$ as well as other organizations as babysitters and relief from their own children"

Respondents expressed a need to have an expert in ADHD available as a consultant to leaders and educators. They also mentioned that there is lack of training on how to work with youth with other disabilities such as Asperger's syndrome and developmental/learning problems. They feel alone when it comes to dealing with youth with special needs. Some of the respondents suggested that as one approach to addressing the lack of training, families of youth with special needs should be encouraged to get involved as helpers and to provide guidance. Factual information, tools and methods (websites, project books, and sensitivity training) should be available to help everyone in the club be successful in their own right and value each other.

\section{Conclusions and Implications}

The findings of this study echo a study conducted by Boone and colleagues (2006) regarding the attitudes and perceptions of extension professionals on including youth with special needs in 4-H programs. In their study, Boone and colleagues concluded that extension professionals are not adequately trained to work with special needs youth despite the fact that the majority of them have special needs youth in their programs. Educators, however, believe that including special needs youth in traditional 4-H programs enhances the development and growth of all youth involved (Boone, et al., 2006). The findings of this study were very similar.

Study results suggest that 4-H leaders find it challenging to foster engaged learning and provide meaningful support for youth with ADHD due to lack of training and support on the disorder. However, the positive perceptions of leaders toward these youth and their willingness to learn are strengths upon which to build, given appropriate support. Leaders are willing to accept youth with ADHD in their programs but need more help to move from simply including the presence of youth with ADHD to the addition of careful planning and consideration, modification of normal routines, activities and provision of necessary support services.

\section{Recommendations for the 4-H Program}

The following recommendations are offered based on the findings and conclusions of this study.

1. Extension Educators and Volunteer Leaders need training on:

- Basic characteristics of ADHD and the issues and problems associated with it

- How to handle and accommodate youth with ADHD in their 4-H club settings 
- How to increase engagement of youth with ADHD in projects with other members in the clubs

- How to adapt project books to more effectively serve youth with ADHD

- Ways to help others understand and accept youth with ADHD

- Techniques of disciplining, and setting expectations for children with ADHD

- Alternative education methods and effective techniques of working with youth with ADHD

- Making club meetings more hands-on and suitable for different learning styles, not just ADHD

2. 4-H should consider learning how the scouting organization has been training its leaders on work with children with special needs and adapt that to 4-H.

3. 4-H should provide information on inclusion of youth with special needs through publications and websites.

\section{Recommendations for Extension Administration}

1. Administration should provide funds for training and resources to help educators and volunteer leaders become more knowledgeable about and work more effectively with youth with special needs.

2. Emphasize the importance of inclusion of youth with special needs in 4-H programs.

3. Hire a specialist with expertise on special needs to serve as a consultant for 4-H.

4. Develop curricular materials that specifically address the needs of special needs youth.

5. Work collaboratively with other youth serving organizations on professional development opportunities that increase the effectiveness of youth development professionals to serve youth with disabilities.

\section{References}

All about 4-H. University of Illinois Extension. (2008). Retrieved November 26, 2008. Available online: http://urbanext.illinois.edu/4H/whatis.html

Boone, D.A., Boone Jr., H.N., Reed, C., Woloshuk, J.M., \& Gartin, S.A. (2006). Attitudes of extension professionals toward involvement of special needs youth with 4-H programs. Journal of Extension, 44(6). Retrieved June 13, 2008. Available online:

http://www.joe.org/joe/2006december/a4.php

Efron, D., Sciberras, E., \& Hassell, P. (2008). Are schools meeting the needs of Students with ADHD? Australasian Journal of Special Education, 32(2), 187-198.

Elhoweris, H., \& Alsheikh, N. (2006). Teachers' attitude toward inclusion. International Journal of Special Education, 21(1), 115-118.

Harrower, J.K., \& Dunlap, G. (2001). Including children with Autism in general education classrooms. Behavior Modification, 25(5), 762-784. Retrieved on June 26, 2008. Available online: http://bmo.sagepub.com/cgi/content/abstract/25/5/762

Hewitt, M. (1999). Inclusion from a general educator's perspective. Preventing School Failure, 43(3) 133-134. 
Humphrey, N. (n.d.). Including pupils with autistic spectrum disorders in mainstream schools. Support For Learning, 23(1), 41-45.

Ingram, P. (1999). Attitudes of extension professionals toward diversity education in 4-H programs. Journal of Extension 3ス1). Retrieved on June 23, 2008 Available online: http://www.joe.org/joe/1999february/a3.html

Jordan, R. (2008). Autism Spectrum Disorders: A challenge and model for inclusion in education. British Journal of Special Education, 35(1), 11-15.

Kent, R.D. (2008). The MIT encyclopaedia of communication disorders: Inclusion models for children with developmental disabilities. Retrieved October 8, 2008. Available online: http://cognet.mit.edu/library/erefs/kent/p03 c028/section1.html

National Institute of Mental Health. (2008). Attention Deficit Hyperactive Disorders, Retrieved June, 2009. Available online: http://purl.access.gpo.gov/GPO/LPS109974

Radhakrishna, R., Cabot, N., \& Everhart, L. (2007). Relationship between 4-H volunteer leaders competencies and skills youth learn in 4-H program. Paper presented at the National Extension Galaxy Conference, Indianapolis, IN.

Tatman, P. (2008). 4-H: An exclusively inclusive program. University of Wyoming Cooperative Extension Services. Retrieved August 20, 2008 from http://uwadmnweb.uwyo.edu/wyo4h/Inclusive/intro.pdf

Tormoehlen, R., \& Field, W.E. (1994). A perfect fit: Youth with disabilities in 4-H. Journal of Extension, 32(1). Retrieved on June 23, 2008 from http://www.joe.org/joe/1994june/a4.php

West Virginia University Extension Services. (2006). Treasure of the trail. Retrieved August 20, 2008. Available online: http://www.wvu.edu/ exten/infores/pubs/fypubs/Treasures.pdf

Weyandat. L.L. (2007). An ADHD primer. NJ: Lawrence Erlbaum Associates.

Wheeler. L., Pumfrey, Wakefield, P., \& Quill, W. (2008). ADHD in schools: Prevalence, multiprofessional involvement and school training needs in an LEA. Emotional and Behavioral Difficulties, 13(2) 163-177.

(C) Copyright of Journal of Youth Development Bridging Research and Practice. Content may not be copied or emailed to multiple sites or posted to a listserv without copyright holder's express written permission. However, users may print, download or email articles for individual use. 